\title{
SMOKING AND ALCOHOL INTAKE AMONG STUDENTS IN MEDICAL COLLEGE OF SOUTH WESTERN REGION, NEPAL
}

\author{
Jha SK ${ }^{1}$, Agrawal $\mathrm{R}^{2}$, Dhakal $\mathrm{PK}^{3}$, Nepal $\mathrm{M}^{4}$, Jayan $\mathrm{A}^{5}$, Gautam $\mathrm{N}^{5}$
}

\begin{abstract}
INTRODUCTION: There is lack of data related to smoking and alcohol intake status with concomitant health and academic related problem to medical students. Hence this study is undertaken to compare smoking and alcohol intake habits among medical students from second to fourth year of their medical education.
\end{abstract}

MATERIAL AND METHODS: A self-directed questionnaire on smoking and alcohol intake habits were distributed among students of second year to fourth year who were willing to participate in this study. All participants were told to fill questions regarding their past and current history of smoking and alcohol intake anonymously.

RESULTS: Out of 300 participants comprising male 201 (67\%) and female 99 (33\%) medical students, the smoker was 27 (9\%) and alcoholic was 61 (20.33\%). There were significantly high frequency of male smoker $24(8 \%)$ and male alcoholic $43(14.33 \%)$ as compared to female smoker $3(1 \%)$ and female alcoholic $18(6 \%)$ respectively. The frequency of smoking and alcohol intake among only male participants was found to be $11.91 \%$ and $21.39 \%$ which is comparable to frequency of only female participants $3.03 \%$ and $18.18 \%$ respectively. The average cigarette consumption before joining medical school was 2.83 day but after joining it has been increased to 5.15 day. Similarly, the average alcohol intake in one sitting was observed $689.26 \mathrm{ml}$ after joining medical college. The average cage questionnaire score for smoker and alcoholic were 0.96 and 1.0 respectively depending on positive response.

CONCLUSION: The high frequency of smoking and alcohol intake among medical students can create havoc in social, health and academic matters. The male students were observed to be more abused in such type of habit as compared to female counterpart. But it is equally important to be noted that the significant less number of female participants and social boundaries for getting cigarette and alcohol might have obscured the actual frequency of their abuse to smoke and alcohol intake. Hence, the health institution should made awareness campaign to the medical students earlier from their entry to the medical school.

KEYWORDS: Smoker, Alcohol intake, Medical students, Nepal

1. Medical Officer, Deuri Parabaha Primary Health Centre, Dhanusha, Nepal

2. Medical Officer, Melamchi Primary Health Centre, Sindhupalchowk, Nepal

3. Medical Officer, Sirthauli Primary Health Centre, Sindhuli, Nepal

4. Dental Officer, Private Dental Practitioner

5. Associate Professor, Department of Biochemistry, Universal College of Medical Sciences \& Teaching Hospital, Bhairahawa, Nepal

\author{
For Correspondence \\ Mr. Narayan Gautam \\ Associate Professor, \\ Universal College of Medical Sciences \& \\ Teaching Hospital, Bhairahawa,Nepal \\ E-mail:ng_bp22@yahoo.com
}




\section{INTRODUCTION}

Tobacco use is among the leading preventable causes of death. Each year, the global tobacco epidemic kills nearly 6 million people, including more than 600,000 who die from exposure to second-hand smoke. It is on track to kill more than 8 million by 2030 , by which time approximately $80 \%$ of the deaths would occur in low- and middle-income countries. ${ }^{1}$ Smoking prevalence in Nepal is higher $(38.4 \%)$ than the smoking prevalence in the world as a whole $(29 \%)$. Tobacco contains nicotine, a substance that is recognized to be addictive. Nicotine fulfils the key criteria for addiction or dependence, including compulsive use, despite the desire and repeated attempts to quit. Cigarettes, unlike chewed tobacco, enable nicotine to reach the brain rapidly, within a few seconds of inhaling smoke, and the smoker can regulate the dose puff by puff. $^{2}$

Medical students who are future doctors have an important role to be played in tobacco cessation and prevention efforts. On the contrary, a vast body of evidence shows that prevalence of tobacco smoking is fairly high among medical students. ${ }^{3}$ Approximately 3.3 million people worldwide die every year due to harmful use of alcohol, this represent $5.9 \%$ of all deaths. The harmful use of alcohol is a causal factor in more than 200 diseases and injury conditions. Overall $5.1 \%$ of the global burden of disease and injury is attributable to alcohol, as measured in disability- adjusted life years (DALYs). Alcohol consumption causes death and disability relatively early in life. In the age group 20-39 years approximately $25 \%$ of the total deaths are alcohol-attributable. ${ }^{1}$

Many studies have reported that tobacco smoking and alcohol intake is rising in young adult between $20-40$ yrs as targets of tobacco and alcohol industry marketing and promotional activities. ${ }^{4}$ Smoking and alcohol have been a part of our society since ancient times. Doctors usually catch an attention of the general public in terms of their personal life as well. There is no such national data available about the number of people involved in it. We conducted this study to analyze the smoking pattern and alcohol intake among the medical students. Strategic policy making will require these data while formulating the actions plans on their control.

\section{MATERIAL AND METHODS}

The convenient sampling was done and self-directed questionnaire was distributed among the study population $(n=300)$ comprised of 201 males and 99 females attending their medical education from second year to fourth years at Universal College of Medical Sciences, Bhairahawa, Nepal.
The purpose of the investigation was explained to all participants before they took part in the study. The participants filled the questionnaire anonymously and responded all questions. The questionnaire comprised of 13 questions related to smoking history and 16 questions related to alcohol history. The last section of the study comprised the "CAGE" questionnaire for the detection of smoking and alcohol dependency. This section was divided into four parts (thinking to cut down of smoking/alcohol, annoyed by using smoking/alcohol, guilty of taking smoking/ alcohol and steady nerves/dependence on smoking/alcohol) with each of the four parts having graded responses. In keeping with the criteria for the CAGE: interview responders who gave positive responses ("no") to more than one of the four questions were designated positive. The total score ranges from 0 to 2 depending upon the positive responses.

The smoking habit was evaluated by the unit "pack-year" which was defined as smoking of a pack of 20 cigarettes per day for one year. The number of pack-years was calculated as: (The number of cigarettes smoked per day * the number of years smoked) / 20. Similarly, alcohol habit was assessed by the Standard measure (1Unit): $25 \mathrm{ml}$ of $40 \%$ alcohol.

The data were expressed in frequency (\%) and mean wherever necessary. The data were fed into excel and statistical analysis was done in Statistical package for Social Service (SPSS-16). The chi-square test is applied to find out significant difference between qualitative variable and the level of significance was set at $\mathrm{p}$-value $<0.05$.

\section{RESULTS}

The figure 1 represents the overall frequency (\%) of male smoker $24(8.0 \%)$ was significantly higher than female smoker $3(1.0 \%)(\mathrm{p}=0.001)$. Out of 300 students, $27(9.0 \%)$ were smoker and $273(81.0 \%)$ were non smoker. The frequency of smoking among only male participants $(n=201)$ was found to be $11.91 \%$ and female participants $(n=99)$ was found to be $3.03 \%$ respectively.

Figure 1: Gender wise frequency $(\%)$ of smoker and non smoker students $(\mathrm{n}=\mathbf{3 0 0})$

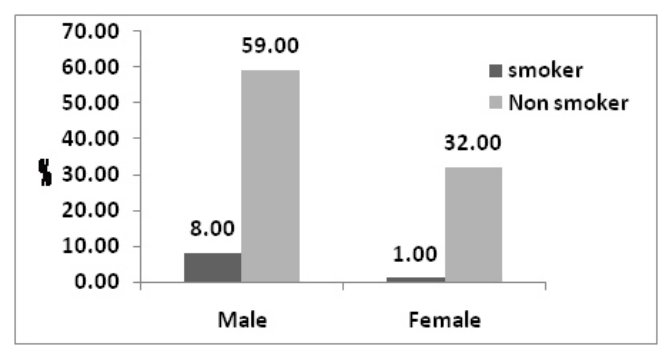


Similarly, the figure 2 represents the overall frequency (\%) of male alcoholic $43(14.33 \%)$ is significantly higher than female alcoholic $18(6.0 \%)(\mathrm{p}=0.0001)$. Out of 300 students, 61(20.33\%) were alcoholic and $239(79.67 \%)$ were non alcoholic. The frequency of alcohol intake among only male participants $(\mathrm{n}=201)$ was $21.39 \%$ and among only female participants ( $\mathrm{n}=99$ ) was $18.18 \%$ respectively.

Figure 2: Gender wise frequency (\%) of alcoholic and non alcoholic students $(n=300)$

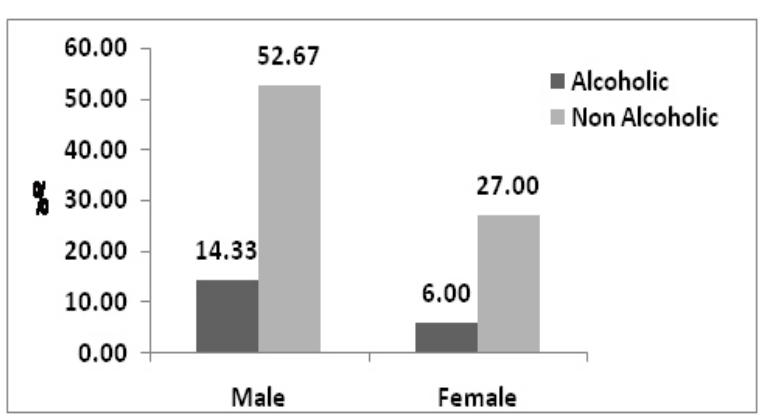

Table 1: Comparison of general variables in smoker $(n=27)$ and alcoholic $(n=61)$

\begin{tabular}{|l|c|c|}
\hline Mean of Variables & $\begin{array}{c}\text { Smoker } \\
(\mathbf{n = 2 7}) \\
16.8 \mathrm{yrs}\end{array}$ & Alcoholic (n=61) \\
Age of starting & $2.86 /$ day & $334.91 \mathrm{ml} /$ one sitting \\
\hline Before joining medical school & $5.15 /$ day & $689.26 \mathrm{ml} /$ one sitting \\
\hline After joining medical school & 4.48 yrs & 3.51 yrs \\
\hline Total duration & 1.15 pack years & 27.57 Unit \\
\hline Standard Unit & $9.23 /$ day & $668.22 \mathrm{ml} /$ one sitting \\
\hline During weekend \& Holiday & $14.13 /$ day & $903.30 \mathrm{ml} /$ one sitting \\
\hline During heaviest period & 0.96 & 1.0 \\
\hline Cage score & & \\
\hline
\end{tabular}

Table 1 shows the general variables between smoker and alcoholic whose mean age of starting smoking and alcohol intake were 16.8 years and 18.16 respectively. There were significant raise in smoking and alcohol intake frequency after joining medical school. Total duration of smoking and alcoholic was found to be 4.48 years and 3.51 years. The data shows the maximum abuse to smoking and alcohol intake occurs during weekend and holiday with heaviest period of smoking 14.13/day and alcohol consumption $903.30 \mathrm{ml}$. The average cage scores for smoking and alcoholic show 0.96 and 1.0 respectively. Table 2 represents the distribution of types of tobacco smoking and alcohol beverages used by smoker and alcoholic. The majority of smoker $(\mathrm{n}=25)$ used filtered cigarette where majority of alcoholic $(\mathrm{n}=21)$ used distilled alcohol beverages.
Table 2: Distribution of types of tobacco smoking and alcoholic beverages

\begin{tabular}{|l|c|}
\hline Type of Tobacco smoking & Frequency (n=27) \\
\hline Filtered Cigarette & 25 \\
\hline Non-Filtered Cigarette & 2 \\
\hline Type of Alcoholic Beverages & Frequency (n=61) \\
\hline Beer & 15 \\
Distilled Alcohol Beverages (Whisky/Gin/Vodka/Rum) & 21 \\
\hline Wine & 6 \\
\hline Local & 2 \\
\hline All types & 17 \\
\hline
\end{tabular}

Table 3 represents the frequency of participants who have tried to stop smoking and alcohol intake were observed maximum response of 10 and 40 for "Never" respectively. Table 4 shows the frequency of participants who response the longest period of time without smoking and alcohol intake were observed maximum for 10 and 40 for "one week or less" and "months to 1 year" respectively.

Table 3: Frequency of response on try to stop smoking and alcohol intake

\begin{tabular}{|l|c|c|}
\hline Response & $\begin{array}{c}\text { Smoker } \\
(\mathbf{n = 2 7})\end{array}$ & $\begin{array}{c}\text { Alcoholic } \\
(\mathbf{n}=\mathbf{6 1})\end{array}$ \\
\hline Never & 10 & 40 \\
\hline one & 3 & 8 \\
\hline two & 2 & 4 \\
three & 3 & 2 \\
\hline four & 2 & 1 \\
\hline five & 1 & 2 \\
\hline six or more & 6 & 4 \\
\hline
\end{tabular}

Table 4: Frequency of response to longest period of time without smoking and alcohol

\begin{tabular}{|l|c|c|}
\hline Response & Smoker $(\mathbf{n}=\mathbf{2 7})$ & Alcoholic $(\mathbf{n}=\mathbf{6 1})$ \\
\hline 1 week or less & 10 & 9 \\
\hline 1 week to month & 8 & 12 \\
\hline$>1$ month to 6 months & 6 & 19 \\
\hline$>6$ months to 1 year & 2 & 20 \\
\hline$>1$ year & 1 & 1 \\
\hline
\end{tabular}

Table 5 shows the maximum participants response "No ill effects observed" with frequency 13 and 42 respectively with smoking and alcohol intake respectively. Table 6 represents response to the interest in stopping smoking and alcohol intake, the maximum participants 10 and 32 replied "Not at all" respectively. 
Table 5: Frequency of response to any ill effects observed due to smoking and alcohol

\begin{tabular}{|l|c|c|}
\hline Response & $\begin{array}{c}\text { Smoker } \\
(\mathbf{n = 2 7})\end{array}$ & $\begin{array}{c}\text { Alcoholic } \\
(\mathbf{n}=\mathbf{6 1})\end{array}$ \\
\hline No ill effects observed & 13 & 42 \\
\hline Health problem & 3 & 6 \\
\hline Social problem & 1 & 2 \\
psychological problem & 2 & 1 \\
\hline relationship problem & 3 & 4 \\
\hline financial problem & 1 & 4 \\
\hline academic problem & 4 & 2 \\
\hline
\end{tabular}

Table 6: Frequency of response to interest in stopping smoking and alcohol intake

\begin{tabular}{|l|c|c|}
\hline Response & $\begin{array}{c}\text { Smoker } \\
(\mathbf{n = 2 7})\end{array}$ & $\begin{array}{c}\text { Alcoholic } \\
(\mathbf{n}=\mathbf{6 1})\end{array}$ \\
\hline strongly & 8 & 7 \\
\hline very & 3 & 6 \\
\hline somewhat & 3 & 10 \\
\hline a little & 3 & 6 \\
not at all & 10 & 32 \\
\hline
\end{tabular}

Table 7 shows response to what prompted to start smoking and alcohol intake, the maximum participants 9 and 23 replied "stress/exam" and "peer pressure" respectively.

Table 7: Frequency of response to what prompted to start smoking and alcohol intake

\begin{tabular}{|l|c|c|}
\hline Response & $\begin{array}{c}\text { Smoker } \\
(\mathbf{n = 2 7 )}\end{array}$ & $\begin{array}{c}\text { Alcoholic } \\
(\mathbf{n}=\mathbf{6 1})\end{array}$ \\
\hline peer pressure & 4 & 23 \\
\hline stress/exam & 9 & 15 \\
\hline advertisement & 7 & 9 \\
\hline $\begin{array}{l}\text { parental } \\
\text { influence }\end{array}$ & 3 & 9 \\
\hline
\end{tabular}

\section{DISCUSSION}

In our study, the smoking and alcohol intake in male students were significantly higher which is similar to results from other survey. The female students were found to be less in number than male counterpart because in our societies smoking and alcohol intake is considered as unacceptable and thought to offend the social costume. ${ }^{3}$ The significantly higher frequency of male smoker and alcoholic were observed than female comparing with individual sex but the number of participants of female were comparatively lower than male participants hence the actual frequency of female smoker and alcoholic were quiet low. The comparable data can be observed in male and female alcoholic $21.39 \%$ and $18.18 \%$ respectively which not only indicate female are also susceptible to get abused in such habit but also reflect knowledge of the greater dangers inherent in heavy drinking and smoking among female students.

It has been reported that the substantial initiation of tobacco and alcohol use occurs before adulthood. ${ }^{5}$ This is in agreement with our findings since the mean age started for smoking was 16.8 years and alcohol intake was 18.16 years. There is concern about raise in smoking and alcohol intake frequency after joining medical school. Moreover, the smoking and alcohol intake were maximum during weekend or holiday with heaviest consumption on those days. Additionally, and in view of the previous findings relating to the age of initiation of smoking, it would appear necessary to establish special antismoking programmes itself in high schools level. ${ }^{6}$

The significant percentage of medical students responded they never tried to stop smoking and alcohol intake and significant percentage told the period without smoking and alcohol were only one week or less and month to years respectively. Their teaching and learning skill as medical students on the adverse effect of smoking and alcohol should be considered with high priority.

The response to the ill effects observed due to smoking and alcohol, the maximum students told "no ill effect observed" and relatively rest of them responses heath and academic problem associated with it. Though recent history is significant for "no ill effect observed", it could be potentially affected with health and academic problem later on their study period as continued with smoking and alcohol intake. The Use of tobacco has been identified as one of the risk factors for contributing to a high prevalence of chronic bronchitis in Nepal. It has been shown that during the early 1980s about $22 \%$ smoking males had chronic bronchitis compared to only $3 \%$ among the non-smokers. Similarly about $24 \%$ smoking females had chronic bronchitis as against about $11 \%$ nonsmoking females.

On response to stimulation for smoking and alcohol intake, maximum response for peer pressure and stress/exam pressure where as other told due to advertisement and parental influence. It should be taken into consideration and proper counseling should be provided to medical students who face 
such type of problems. In one of the survey done in general population, the majority of respondents $(52.5 \%)$ who ever smoked did so because of influence from friends. The second most important reason for smoking appears to be the influence of parents or other senior family members who smoked. ${ }^{8}$

The dependency of medical students on smoking and alcohol intake can be observed from the CAGE score range from 0 to 2 with $50 \%(0.96 \& 1$ respectively) mean positive response. Medical students do seem to be more aware of the dangers of excess alcohol than the general population, as has been shown for smoking.

Medical students present an interesting paradox, consuming excessive amounts of alcohol despite having a high awareness of safe limits of drinking. If education on alcohol abuse and its consequences is increasing this picture may represent student knowledge preceding changes in behavior. ${ }^{10} \mathrm{Hence}$, it is better to find out the current problem associated with smoking and alcohol intake habit if we wish to curtail present number.

\section{CONCLUSIONS:}

Since our study has considered a convenient sample of our medical school can only provide about the medical school we surveyed. Therefore, our results cannot be applied to other medical schools. However, our study provides the platform for generating nation-wide data and associated problems with smoking and alcohol intake habit.

\section{ACKNOWLEDGEMENT}

We would like to acknowledge all medical students and whoever have directly or indirectly help to accomplish this work.

\section{REFERENCES}

1. WHO official website http://www.who.int/tobacco/economics len/ \& http://www.who.int/mediacentre/factsheets/fs349/en/ [Accessed on 8th August 2014]

2. The National Anti-tobacco Communication Campaign Strategy for Nepal. http://www.mohp.gov.np/English/files/new.../9-3Tobacco-Control-Act.pdf

3. Chandrashekhar TS, Sushil S, Ritesh G M, Harsha KHN, Mahbubur R, Md RI, et al. Self-reported tobacco smoking practices among medical students and their perceptions towards training about tobacco smoking in medical curricula: A crosssectional, questionnaire survey in Malaysia, India, Pakistan, Nepal, and Bangladesh. Substance Abuse Treatment, Prevention, and Policy 2010, 5:29,1-9.
4. Lovato C, Watts A, Stead LF. Impact of tobacco advertising and promotion on increasing adolescent smoking behaviours. Cochrane Database of Systematic Reviews. 2011;(10):CD003439. PMid:21975739

5. Jackson C. Cognitive susceptibility to smoking and initiation of smoking during childhood: a longitudinal study. Prev Med 1998; 27:129-34. http://dx.doi.org/10.1006/pmed.1997.0255 PMid:9465363http://dx.doi.org/10.1006/pmed.1997.0255

6. Ioannis NM, George KB, Manolis L, Nikolaos ET, Demetre NL, Anthony GK. Cigarette smoking, alcohol consumption, and serum lipid profile among medical students in Greece. European Journal of Public Health 2003; 13: 27882. http://dx.doi.org /10.1093/eurpub/13.3.278http://dx.doi.org/10.1093/eurpub/13. 3.278

7. Pandey MR et al. Chronic Bronchitis and Cor Pulmonale in Nepal. A Scientific Epidemiological Study, Mrigrendra Medical Trust, Kathmandu, Nepal, 1988.

8. Pande BR, Karki YB, Pant K. A Study on Tobacco Economics in Nepal, 2000. Submitted to WHO/SEARO, New Delhi, 2001.

9. Plant M. Drugs in perspective. Lonidon: Hoddcr and Stotughton, 1987.

10. DJ Collier, ILP Beales. Drinking among medical students: a questionnaire survey. BMJ 1989; 299: 19-22. http://dx.doi.org/ 10.1136/ bmj.299.6690.19 PMid:2503193 PMCid: PMC 1836972

http://dx.doi.org/10.1136/bmj.299.6690.19 